\title{
ANÁLISE ENERGÉTICA DE CERVEJA ELABORADA COM MEL ${ }^{1}$
}

\author{
Luciana Trevisan Brunelli² \&Waldemar Gastoni Venturini Filho ${ }^{3}$
}

RESUMO: O objetivo deste trabalho foi comparar os teores de nutrientes (carboidratos, proteínas e gorduras totais) e valores energéticos informados nos rótulos de bebidas não-alcoólicas comerciais de manga e de goiaba com os resultados encontrados em análises laboratoriais e padrões estabelecidos pela legislação brasileira. Dentre as bebidas de manga, foram analisadas quatro marcas de sucos tropicais não adoçados, três adoçados, seis néctares convencionais e três light. Dentre as de goiaba, quatro sucos tropicais não adoçados, três adoçados, cinco néctares convencionais e três light. Os teores de carboidratos, proteínas e gorduras totais foram obtidos através de análise química dessas bebidas, enquanto que os seus valores energéticos foram estimados através de cálculo centesimal, utilizando fatores de conversão para carboidratos $(4 \mathrm{kcal} / \mathrm{g})$, proteínas $(4 \mathrm{kcal} / \mathrm{g})$ e gorduras totais $(9 \mathrm{kcal} / \mathrm{g})$. As bebidas cujos teores de nutrientes e valores energéticos obtidos em laboratório excederam o intervalo de tolerância de $\pm 20 \%$, calculado a partir dos dados declarados em suas embalagens, foram consideradas fora dos padrões de qualidade. Das dezesseis bebidas comerciais de manga analisadas, metade declarou os teores de nutrientes e valores energéticos, em conjunto, de maneira correta em seus rótulos. Enquanto que, das quinze de goiaba, cinco puderam ser consideradas dentro dos padrões de qualidade.

PALAVRAS-CHAVE: bebida alcoólica, composição centesimal, valor calórico e valor energético.

\section{ENERGY ANALYSIS OFBEERPRODUCEDWITH HONEY}

\begin{abstract}
The objective of this study was to characterize energetically beersmade withhoney. The tests of beer production weremade withninetreatments, threecombination of the originalextract concentrations (11, 13and 15 ${ }^{\circ}$ Brix) and threepercentagesof honeyin the wort formulation( 0,20 and 40\%).The experimentwas completely randomizedwith two replications, totaling eighteenplots. Themashingprocesswas performed byinfusion, with honey added in the boiling step. After clarified, the wort had its extract contents corrected with the addition of filtered water and was inoculated withlowfermentation yeast.The fermentation occurred at $10^{\circ} \mathrm{C}$. The beer was manually bottled and stored in a freezer at $0{ }^{\circ} \mathrm{C}$ for 15 days, formaturation. The beers were chemically analyzed on proximate composition (moisture, protein, lipid, ash, and carbohydrate), alcohol content $(\% \mathrm{~m} / \mathrm{m})$ and then calculated the energy value. The results ofchemical analysis andenergetic valuesof the beerswere subjected to analysisof variance (F test) and the means werecompared byTukey testat $5 \%$ probability. The commonbeershad the lowestenergy value

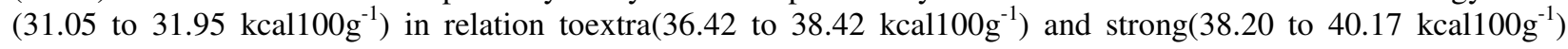
beers. Theincrease in the original extractin beerraises theircaloric values. The presenceof honeyin the formulationincreasedthe energetic valuesincommon andextrabeersand decreasedin strong.The levelsof alcohol andcarbohydratewere predominant in thebeer energetic values,beingpossible to observeadirect relation amongthese components ofbeer and theircaloric value.
\end{abstract}

KEYWORDS: alcoholic beverage, chemical composition, calorificvalue and energy value.

\footnotetext{
1 Parte da dissertação de mestrado do $1^{\circ}$ autor intitulada: Produção de cerveja com mel: características físico-químicas, energética e sensorial. ${ }^{2}$ Aluna do Programa de Pós-graduação em Agronomia - Energia na Agricultura, FCA/UNESP - Botucatu/SP - Brasil, engenheira agrônoma. Rua José Barbosa de Barros, n 1780, Cep: 18.610-307,
}

\footnotetext{
E-mail: lutbrunelli@gmail.com

${ }^{3}$ Orientador e docente do Departamento de Horticultura, FCA/UNESP - Botucatu/SP - Brasil. Rua José Barbosa de Barros, nº1780, Cep: 18.610-307, E-mail: venturini@fca.unesp.br
} 


\section{INTRODUÇÃO}

A China, com uma produção de 44,8 bilhões de litros, é a maior produtora mundial de cerveja, seguida dos EUA $(22,8)$, Brasil $(11,4)$, Rússia $(10,3)$ e Alemanha $(9,6)$ (BARTH..., 2011). O Brasil, no ano de 2010, ultrapassou a Rússia, alcançando o terceiro lugar. A cerveja tipo Pilsen (ou Pilsener) é a líder absoluta na preferência dos consumidores mundiais e corresponde a $98 \%$ do mercado brasileiro de cerveja (SOARES, 2011).

A tendência do setor, confirmada por especialistas, fabricantes e cervejeiros, segue os passos de outras partes do mundo, como nos Estado Unidos, onde uma revolução no consumo fez aumentar o número de microcervejarias existentes no país. No Brasil, o processo é lento, mas está ocorrendo gradativamente e com mais intensidade nos últimos anos. A expansão das microcervejarias é resultado da curiosidade dos consumidores pelas chamadas cervejas especiais (SOARES, 2011).

A tendência do mercado cervejeiro brasileiro é sem dúvida a segmentação, devido aos consumidores dispostos a experimentar produtos diferenciados como cerveja sem álcool, de trigo, milho, com limão, mel, mandioca, misturada com frutas, como a framboesa, de baixa ou alta fermentação. Assim, os diversos tipos de cerveja existentes devem ficar mais populares, com os fabricantes voltados aos nichos específicos e disponibilizando inúmeras variações da bebida no mercado, justamente para atender a este novo perfil de consumidor (SOARES, 2011).

A composição dos alimentos é fundamental para obter a segurança alimentar e nutricional. As informações de uma tabela de composição de alimentos são essenciais para o controle da qualidade dos alimentos bem como a avaliação da ingestão de nutrientes de uma população. Por meio delas, é possível efetuar a rotulagem nutricional a fim de auxiliar consumidores na escolha dos alimentos, orientarem a produção agrícola e as indústrias de alimentos no desenvolvimento de novos produtos, além de permitir as autoridades de saúde pública de estabelecer metas nutricionais e guias alimentares que levem a uma dieta mais saudável (TACO, 2011).

O valor energético de um alimento pode ser determinado de forma direta por bomba calorimétrica, indireta por meio da análise centesimal e pela tabela de composição de alimentos e bebidas. A determinação do valor energético de forma indireta (análise centesimal) de um alimento é feita considerando o calor de combustão e a digestibilidade de proteínas, lipídios e carboidratos; e quando presente, pelo teor de álcool. O cálculo para obtenção do valor energético é feito a partir dos teores de carboidratos, proteínas, lipídeos e álcool, utilizando fatores de conversão de 3,$75 ; 4 ; 9$ e $7 \mathrm{Kcal} \mathrm{g}^{-1}$, respectivamente (MOREIRA et al., 2005; SOUTHGATE; DURNIN, 1970).
Embora exista recomendação, há mais de 30 anos, para utilizar somente o Joule, como unidade de valor energético em alimentos e bebidas, cientistas, nutricionistas e consumidores ainda possuem dificuldade em recusar o termo caloria. Devido a esse fato, na rotulagem nutricional dos produtos alimentícios, os valores energéticos precisam ser expressos em ambas as unidades (FAO, 2003).

A legislação brasileira define cerveja como “... a bebida obtida pela fermentação alcoólica do mosto cervejeiro oriundo do malte de cevada e água potável, por ação da levedura, com adição de lúpulo". Parte do malte de cevada poderá ser substituída por adjuntos cervejeiros, cujo emprego não poderá ser superior a $45 \%$ em relação ao extrato primitivo, isto é, extrato do mosto de malte (BRASIL, 2009).

Quanto à proporção de malte de cevada, as cervejas podem ser classificadas em: a) "cerveja de puro malte", aquela que possuir $100 \%$ de malte de cevada em peso, sobre o extrato primitivo, como fonte de açúcares; b) "cerveja", aquela que possuir proporção de malte de cevada maior ou igual a $55 \%$ em peso, sobre o extrato primitivo, como fonte de açúcares; c) "cerveja de ...", seguida do nome do vegetal predominante, aquela que possuir proporção de malte de cevada maior que $20 \%$ e menor que $55 \%$, em peso, sobre o extrato primitivo, como fonte de açúcares (BRASIL, 2009).

As cervejas são classificadas quanto ao extrato primitivo em: a) cerveja leve, cujo extrato primitivo é maior ou igual a $5 \%$ em peso e menor do que $10,5 \%$ em peso; b) cerveja ou cerveja comum, cujo extrato primitivo é maior ou igual a $10,5 \%$ em peso e menor que $12 \%$ em peso; c) cerveja extra, cujo extrato primitivo é maior ou igual a $12 \%$ em peso e menor ou igual a $14 \%$ em peso; d) cerveja forte, cujo extrato primitivo é maior que $14 \%$ em peso (BRASIL, 2009).

O objetivo do presente trabalho foi caracterizar energeticamente cervejas elaboradas com mel.

\section{MATERIAL E MÉTODOS}

\subsection{Planejamento experimental}

O trabalho experimental e as análises químicas e energéticas foram realizadosde janeiro a novembro de 2011, no Laboratório de Bebidas, Departamento de Horticultura, Faculdade de Ciências Agronômicas, UNESP, Campus de Botucatu. O Laboratório dispõe de planta piloto da empresa Harmo Darin (Mec Bier), fabricada em aço inoxidável com capacidade de 50 litros para produção de cervejas.

Os ensaios da produção de cerveja foram feitos com nove tratamentos, combinação de três concentrações de extrato primitivo $\left(11,13\right.$ e $15^{\circ}$ Brix) e três porcentagens de mel na formulação do mosto $(0,20$ e $40 \%)$. O delineamento experimental foi inteiramente casualizado em esquema fatorial $3 \times 3$, com duas repetições, 
perfazendo dezoito parcelas experimentais. Os resultados das análises químicas e valor energético das cervejas foram submetidos à análise de variância (teste F) e as médias foram comparadas pelo teste de Tukey, ao nível de 5\% de probabilidade (VIEIRA, 2006).

\subsection{Protocolo da fabricação da cerveja}

A moagem do malte foi a seco, em moinho de dois rolos (Mc Bier). Na mosturação, utilizou-se o processo de infusão (Figura 1), sendo que a proporção malte $(4 \mathrm{~kg})$ e água(12 kg) foi de 1 para 3 (KUNZE, 2006). Ao final da mosturação realizou-se o teste de iodo, para confirmação da sacarificação do amido.

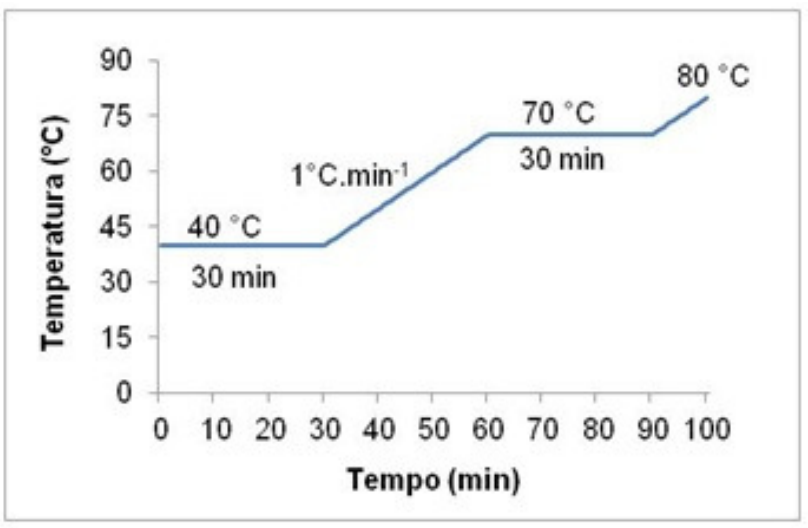

Figura 1: Programação de tempo e temperatura no processo de mosturaçao por infusão.

O mosto (primário) foi separado do bagaço de malte por filtração convencional, sendo a torta de filtro lavada com $8 \mathrm{~kg}$ de água a $80^{\circ} \mathrm{C}$, para extração do açúcar residual, obtendo o mosto secundário. A mistura de ambos (mosto misto) foi fervida à pressão atmosférica durante 60 minutos. Durante a fervura do mosto, adicionou-se lúpulo em péletes pelo método das três cargas (HUDSTON, 1977) e no mesmo instante da última carga de lúpulo, o mel de laranjeira foi adicionado ao mosto na proporção de 0,20 e $40 \%$, com base no extrato, sendo sua quantidade calculada a partir das equações 1 e 2 .

$\%$ de $\mathrm{mel}=\left(\begin{array}{c}\text { Mextrato mel } \\ \text { Mexirato mel }- \text { Mextrato malte }\end{array}\right) \cdot 100$

Onde:

$\%$ de mel $=$ percentual de mel na formulação, na base do extrato;

M extrato mel = massa de extrato de mel;

$\mathrm{M}$ extrato malte $=$ massa de extrato de malte.

Brix $=\frac{\text { M extrats mel }}{\text { M mel }} \cdot 100$

Onde:

Brix = teor de extrato ou sólidos solúveis do mel;
M extrato mel = massa de extrato do mel;

M mel = massa de mel a ser adicionada ao mosto de malte.

Após a fervura, realizou-se a operação do whirlpool, durante 5 minutos. Após esse período, ocorreu o repouso de 60 minutos visando a separação do trub, por decantação.

O mosto clarificado foi transferido para o fermentador, e seu teor de extrato foi corrigido para 11,13 e $15^{\circ}$ Brix, através da adição de água, conforme equação 3 . O mosto corrigido foi resfriado a $10{ }^{\circ} \mathrm{C}$ e inoculado com levedura cervejeira de baixa fermentação da espécie Saccharomycescerevisiae centrifugada $(4000 \mathrm{rpm} / 5$ $\mathrm{min}$ ) na proporção de $1 \%(\mathrm{~m} / \mathrm{m})$, iniciando o processo de fermentação.

$\mathrm{B} 1 . \mathrm{M} 1+\mathrm{B} 2 . \mathrm{M} 2=\mathrm{B} 3 . \mathrm{M} 3$

Onde:

B1 = Brix do mosto inicial;

M1 = massa do mosto inicial;

B2 = Brix da água;

M2 = massa de água;

B3 = Brix do mosto final;

M3 = massa do mosto final.

Antes da inoculação, $200 \mathrm{~mL}$ de mosto corrigido foi separado e inoculado com aproximadamente $20 \mathrm{~g}$ de fermento cervejeiro centrifugado e colocado para fermentar em temperatura ambiente até a estabilização do teor de extrato (atenuação limite). A fermentação foi acompanhada diariamente, até o mosto apresentar o valor de $1{ }^{\circ}$ Brix acima da atenuação limite. Posteriormente, a cerveja foi engarrafada manualmente em garrafas de vidro âmbar de $600 \mathrm{~mL}$ e colocadas em freezer à temperatura de $0{ }^{\circ} \mathrm{C}$ por 15 dias, para maturação. A carbonatação ocorreu na própria garrafa, através da fermentação do açúcar residual presente na cerveja, por ação de leveduras remanescentes.

\subsection{Análises químicas}

As cervejas foram analisadas quanto à composição centesimal (umidade, proteína, lipídio, cinzas e carboidrato), ao teor alcoólico $(\% \mathrm{~m} / \mathrm{m})$ e, posteriormente, calculou-se o valor energético. As análises foram feitas em triplicatas.

- Álcool: o teor alcoólico foi determinado pelo método da destilação. A densidade relativa do destilado foi determinada em densímetro digital e depois convertida em teor alcoólico (\% v/v) por meio de tabela (BRASIL, 2005). O teor alcoólico em $\% \mathrm{v} / \mathrm{v}$ foi convertido em $\%$ $\mathrm{m} / \mathrm{m}$ por meio da equação 4 .

Teor alcoólico $=\left(\frac{\text { V tanol } \cdot D \text { etanol }}{\text { V sol } \cdot D \text { sol }}\right) \cdot 100$ 
Onde:

$\mathrm{V}$ etanol $=$ volume de etanol do destilado, $\mathrm{em} \mathrm{mL}$;

D etanol = densidade do etanol, 0,789 g. $\mathrm{mL}^{-1}$;

$\mathrm{V}$ sol = volume do destilado, $100 \mathrm{~mL}$;

$\mathrm{D}$ sol $=$ densidade do destilado, em g.mL ${ }^{-1}$

- Umidade:o teor de umidade foi determinado pelo método de secagem em estufa, através da perda de peso da amostra, quando aquecida a $105^{\circ} \mathrm{C}$ (BRASIL, 2005).

- Cinzas: o teor de cinzas foi determinado por incineração em mufla a $550^{\circ} \mathrm{C}$ (BRASIL, 2005).

- Lipídio: o lipídio total foi determinado pelo método proposto por Bligh e Dyerm (1959).

- Proteína: o teor de proteína bruta foi determinado a partir do teor de nitrogênio total, usando fator 6,25 , pelo método Kjeldahl modificado (BRASIL, 2005).

- Carboidrato: o teor de carboidrato foi calculado pela diferença entre 100 e a soma dos demais constituintes (umidade, proteínas, lipídios, cinzas e álcool) (TACO, 2011 e MOREIRA et al., 2005).

\subsection{Determinação do valor energético}

Os valores energéticos das bebidas foram expressos em kcal e kJ. Esses valores foram calculados a partir da concentração de proteína, lipídio, carboidrato e álcool, utilizando os fatores energéticos de conversão proposto por Southgate e Durnin (1970).

- Proteína: 4 kcal $100 \mathrm{~g}^{-1}$;

- Lipídio: 9 kcal $100 \mathrm{~g}^{-1}$;

- Carboidrato: 3,75 kcal $100 \mathrm{~g}^{-1}$;

- Álcool: $7 \mathrm{kcal} 100 \mathrm{~g}^{-1}$.

Os valores energéticos expressos em $\mathrm{kJ}$ foram estimados a partir dos valores em kcal multiplicado diretamente pelo fator de conversão 4,184.

$\mathrm{VE}=\mathrm{FC} . \mathrm{CN}$

Onde:

$\mathrm{VE}=$ valor energético $\left(\mathrm{kcal} 100 \mathrm{~g}^{-1}\right)$;

$\mathrm{FC}=$ fator de conversão específico $\left(\mathrm{kcal} \mathrm{g}^{-1}\right)$;

$\mathrm{CN}=$ concentração do componente nutricional na bebida $\left(\mathrm{g} 100 \mathrm{~g}^{-1}\right)$.

\section{RESULTADOS E DISCUSSÃO}

Os valores médios da composição centesimal e valor energético das cervejas estão apresentados na Tabela 1.
Tabela 1: Composição centesimal e valor energético de cerveja comum (11 ${ }^{\circ}$ Brix), extra (13 ${ }^{\circ}$ Brix) e forte (15 Brix) por 100 gramas de bebida.

\begin{tabular}{|c|c|c|c|c|c|c|c|c|c|}
\hline 肴 & 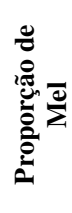 & 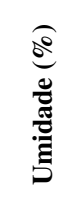 & 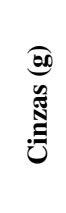 & 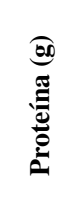 & م0 & 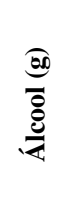 &  & 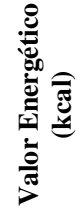 & 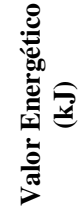 \\
\hline \multirow{3}{*}{11} & $\mathbf{0 \%}$ & 90,65 & 3,42 & 0,72 & 0,18 & 3,18 & 1,29 & 31,05 & 130,12 \\
\hline & $20 \%$ & 91,04 & 3,16 & 0,49 & 0,15 & 3,36 & 1,12 & 31,11 & 130,17 \\
\hline & $40 \%$ & 91,76 & 3,11 & 0,38 & 0,12 & 3,84 & 0,64 & 31,95 & 133,67 \\
\hline \multirow{3}{*}{13} & $0 \%$ & 90,18 & 3,67 & 0,74 & 0,16 & 3,78 & 1,48 & 36,42 & 152,38 \\
\hline & $20 \%$ & 90,77 & 3,16 & 0,50 & 0,11 & 4,50 & 0,96 & 38,12 & 159,50 \\
\hline & $40 \%$ & 90,63 & 3,30 & 0,42 & 0,10 & 4,63 & 0,92 & 38,42 & 160,76 \\
\hline \multirow{3}{*}{15} & $0 \%$ & 89,98 & 3,98 & 0,79 & 0,14 & 4,33 & 1,44 & 40,17 & 168,08 \\
\hline & $20 \%$ & 90,62 & 3,84 & 0,52 & 0,08 & 4,37 & 1,17 & 37,60 & 157,33 \\
\hline & $40 \%$ & 90,77 & 3,45 & 0,46 & 0,06 & 4,72 & 0,81 & 38,20 & 159,81 \\
\hline
\end{tabular}

As significâncias estatísticas obtidas pelo teste $\mathrm{F}$ para as análises químicas e valores energéticos realizadas nas cervejas estão mostrados na Tabela 2.

Tabela 2: Significâncias estatísticas obtidas pelo teste $F$ para as análises químicas e valores energéticos realizadas nas cervejas.

\begin{tabular}{|c|c|c|c|}
\hline Parâmetros & $\begin{array}{c}\text { Concentração } \\
\text { de extrato } \\
\text { primitivo } \\
(11,13 \text { e } \\
\left.1^{\circ} \text { Brix }\right)\end{array}$ & $\begin{array}{c}\text { Porcentagem } \\
\text { de mel } \\
(0,20 \text { e } 40 \%)\end{array}$ & $\begin{array}{c}\text { Interação } \\
\text { extrato } \\
\text { primitivo } x \\
\text { porcentagem } \\
\text { de mel }\end{array}$ \\
\hline Umidade & $* *$ & ** & ** \\
\hline Cinzas & $* *$ & $* *$ & $* *$ \\
\hline Proteína & ns & $* *$ & ns \\
\hline Lipídios & ns & $* *$ & ns \\
\hline Carboidrato & ns & $* *$ & ns \\
\hline Álcool & $* *$ & $* *$ & $\mathrm{~ns}$ \\
\hline $\begin{array}{l}\text { Valor } \\
\text { energético }\end{array}$ & $* *$ & $* *$ & $* *$ \\
\hline
\end{tabular}

** significativo ao nível de $1 \%$ de probabilidade $(\mathrm{p}<0,01)$.

ns: não significativo $(\mathrm{p} \geq 0,05)$.

O teor de proteína das cervejas foi influenciado pela adição de mel (Tabela 2). As cervejas elaboradas com mel apresentaram menores teores médios de proteína 
$(0 \%-0,75 a ; 20 \%-0,50 b$ e $40 \%-0,42 c)$. Fato explicado devido aos baixos teores desse composto no mel, em média 0,44\% (PEREIRA et al., 2003), enquanto o malte deve apresentar no máximo 11,5\% (REINOLD, 1995).

Os teores de lipídios das cervejas sofreram influência das diferentes porcentagens de mel na formulação (Tabela 2). O mel apresenta baixo teor de lipídios, em média $0,15 \%$ (SOUZA et al., 2005). Em função disso, as cervejas com mel apresentaram teores médios de lipídios inferiores às elaboras apenas com malte $(0 \%-0,16 \mathrm{a}$; $20 \%-0,11 \mathrm{~b} 40 \%-0,08 \mathrm{~b})$.

$\mathrm{O}$ mel influenciou significativamente os teores de carboidrato das cervejas (Tabela 2). Os carboidratos do mel são constituídos basicamente por açúcares fermentescíveis $(34 \%$ de glicose, $41 \%$ de frutose e apenas 1,5\% de dextrina) (PEREIRA et al., 2003), enquanto que o mosto de malte apresenta açúcares fermentescíveis e dextrina infermentescível $(13,81 \%$ de maltotriose, $47,15 \%$ de maltose, $8,04 \%$ de glicose, $1,17 \%$ de frutose, $3,27 \%$ de sacarose e $26,54 \%$ de dextrina) (BRIGGS, 2004). Portanto, as cervejas elaboradas sem mel apresentaram os maiores teores médios de carboidrato (0\% - 1,40a; $20 \%$ - 1,08b e $40 \%$ $0,79 \mathrm{c})$, em virtude da maior presença de carboidratos infermentescíveis (dextrina) nos mostos das cervejas puro malte.

Tanto o mel quanto o extrato primitivo interfeririam nos teores de álcool das cervejas (Tabela 2). As cervejas elaboradas com o menor teor de extrato primitivo $\left(11^{\circ}\right.$ Brix $)$, isto é, menor concentração de açúcares, apresentaram os menores teores alcoólicos (comum $3,46 \mathrm{c}$; extra $-4,30 \mathrm{~b}$ e forte $-4,48 \mathrm{a})$. As cervejas elaboradas com $40 \%$ de mel apresentaram teores alcoólicos médios superiores em relação às elaboradas sem mel ( $0 \%$ - 3,76c; $20 \%$ - 4,08b e $40 \%$ - 4,40a), pois o mel é constituído basicamente por açúcares fermentescíveis enquanto que o mosto de malte apresenta açúcares fermentescíveis e dextrina infermentescível, como discutido anteriormente. Em função da elevada fermentabilidade do mel, esperava-se que as cervejas elaboradas com esta matéria-prima apresentassem teores alcoólicos mais elevados, mas isso apenas foi verificado nas cervejas com $40 \%$ de mel.
Tabela 3: Efeito do mel, do extrato primitivo e da interação nos teores de umidade $e$ cinzas das cervejas.

\begin{tabular}{|c|c|c|c|c|}
\hline \multirow{2}{*}{ 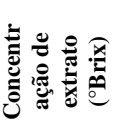 } & \multicolumn{3}{|c|}{ Porcentagem de Mel (\%) } & \multirow{2}{*}{ Média } \\
\hline & $0 \%$ & $20 \%$ & $40 \%$ & \\
\hline \multicolumn{5}{|c|}{ Umidade (\%) } \\
\hline 11 & $90,65 \mathrm{aC}$ & $91,04 \mathrm{aB}$ & $91,76 \mathrm{aA}$ & $91,15 \mathrm{a}$ \\
\hline 13 & 90,18 bB & $90,77 \mathrm{abA}$ & $90,63 \mathrm{bA}$ & $90,53 \mathrm{~b}$ \\
\hline 15 & 89,98 bB & 90,62 bA & $90,77 \mathrm{bA}$ & $90,45 \mathrm{~b}$ \\
\hline Média & $90,27 \mathrm{c}$ & $90,80 \mathrm{~b}$ & $91,06 \mathrm{a}$ & \\
\hline \multicolumn{5}{|c|}{ Cinzas (g) } \\
\hline 11 & $3,42 \mathrm{bA}$ & $3,16 \mathrm{bB}$ & $3,11 \mathrm{bB}$ & $3,69 \mathrm{a}$ \\
\hline 13 & $3,67 \mathrm{bA}$ & $3,16 \mathrm{bB}$ & $3,30 \mathrm{abB}$ & $3,37 \mathrm{~b}$ \\
\hline 15 & $3,98 \mathrm{aA}$ & $3,84 \mathrm{aA}$ & $3,45 \mathrm{aB}$ & $3,26 \mathrm{~b}$ \\
\hline Média & $3,66 \mathrm{a}$ & $3,42 \mathrm{~b}$ & $3,25 \mathrm{c}$ & \\
\hline \multicolumn{5}{|c|}{ Proteína (g) } \\
\hline 11 & 0,72 & 0,49 & 0,38 & 0,53 \\
\hline 13 & 0,74 & 0,50 & 0,42 & 0,56 \\
\hline 15 & 0,79 & 0,51 & 0,46 & 0,59 \\
\hline Média & $0,75 \mathrm{a}$ & $0,50 \mathrm{~b}$ & $0,42 \mathrm{c}$ & \\
\hline \multicolumn{5}{|c|}{ Lipídio (g) } \\
\hline 11 & 0,18 & 0,16 & 0,12 & 0,16 a \\
\hline 13 & 0,16 & 0,11 & 0,10 & $0,11 \mathrm{~b}$ \\
\hline 15 & 0,14 & 0,06 & 0,03 & $0,08 \mathrm{~b}$ \\
\hline Média & $0,15 \mathrm{a}$ & $0,12 \mathrm{a}$ & $0,08 \mathrm{~b}$ & \\
\hline \multicolumn{5}{|c|}{ Álcool (g) } \\
\hline 11 & 3,18 & 3,36 & 3,84 & $3,46 \mathrm{c}$ \\
\hline 13 & 3,78 & 4,50 & 4,63 & $4,30 \mathrm{~b}$ \\
\hline 15 & 4,33 & 4,37 & 4,72 & 4,48 a \\
\hline Média & $3,76 \mathrm{c}$ & $4,08 \mathrm{~b}$ & $4,40 \mathrm{a}$ & \\
\hline \multicolumn{5}{|c|}{ Carboidrato (g) } \\
\hline 11 & 1,29 & 1,11 & 0,64 & 1,01 \\
\hline 13 & 1,49 & 0,96 & 0,92 & 1,12 \\
\hline 15 & 1,44 & 1,17 & 0,81 & 1,14 \\
\hline Média & $1,40 \mathrm{a}$ & $1,08 \mathrm{~b}$ & $0,79 \mathrm{c}$ & \\
\hline \multicolumn{5}{|c|}{ Valor Energético (kcal) } \\
\hline 11 & $31,05 \mathrm{cB}$ & $31,11 \mathrm{bB}$ & $31,95 \mathrm{bA}$ & $31,54 \mathrm{c}$ \\
\hline 13 & $36,42 \mathrm{bB}$ & $38,12 \mathrm{aA}$ & $38,42 \mathrm{aA}$ & $37,65 \mathrm{~b}$ \\
\hline 15 & $40,17 \mathrm{aA}$ & $37,60 \mathrm{aB}$ & $38,20 \mathrm{aB}$ & 38,66 a \\
\hline Média & 36,05 & 35,61 & 36,19 & \\
\hline \multicolumn{5}{|c|}{ Valor Energético (kJ) } \\
\hline 11 & $130,12 \mathrm{cB}$ & $130,17 \mathrm{bB}$ & $133,67 \mathrm{bA}$ & $131,94 \mathrm{c}$ \\
\hline 13 & $152,38 \mathrm{bB}$ & $159,50 \mathrm{aA}$ & $160,76 \mathrm{aA}$ & $157,5 \mathrm{~b}$ \\
\hline 15 & $168,08 \mathrm{aA}$ & $157,33 \mathrm{aB}$ & $159,81 \mathrm{aB}$ & $161,74 \mathrm{a}$ \\
\hline Média & $150,81 \mathrm{a}$ & 148,99 a & $151,42 \mathrm{a}$ & \\
\hline
\end{tabular}

Médias seguidas pela mesma letra maiúscula na linha e pela mesma letra minúscula na coluna, não diferem entre si, a 5\% de probabilidade, pelo teste Tukey. 
As diferentes concentrações de extrato primitivo, as porcentagens de mel e a interação de ambos influenciaram os teores de umidade das cervejas (Tabela 2). As cervejas comuns apresentaram teores de umidade mais elevados (Tabela 3), pelo fato de terem sido fabricados com mostos mais diluídos (11 ${ }^{\circ}$ Brix). As cervejas fabricadas com mel também apresentaram umidade mais elevadas (Tabela 3); pelo fato de conterem menos dextrinas, carboidrato não fermentescível que permanece na cerveja como extrato. Os carboidratos do mel são fermentescíveis e convertidos em etanol durante a fermentação alcoólica; este por ser volátil será computado como parte da umidade da cerveja.

Os teores de cinzas das cervejas foram influenciados pelo extrato primitivo, pelo mel e a interação desses dois fatores (Tabela 2). As cervejas elaboradas apenas com malte apresentaram os maiores teores de cinzas (Tabela 3). Comportamento esperado, pois segundo Venturini Filho (1996), o malte é constituído por 1,97\% de cinzas, enquanto o mel apresenta em média $0,17 \%$ (PEREIRA et al., 2003). Os teores de cinzas nas cervejas fortes foram mais elevados em função da maior riqueza de extrato (açúcares, minerais, etc.) nessas cervejas (Tabela 2).

Segundo Briggs (2004), o valor energético de cerveja tipo Pilsen puro malte, pode variar de 143,6 a 172,0 kJ $100 \mathrm{~g}^{-1}$. Entretanto, Moreia et al. (2005) e TACO (2011)

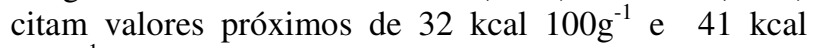
$100 \mathrm{~g}^{-1}$, respectivamente.

A adição de mel, as diferentes concentrações de extrato primitivo e a interações entre ambos interfeririam significativamente no valor energético das cervejas (Tabela 2). As cervejas comuns (Tabela 3) apresentaram os menores valores energéticos (31,05a 31,95 $\left.\mathrm{kcal} 100 \mathrm{~g}^{-1}\right)$ em relação às cervejas fortes $(36,42$ a 38,42 kcal $\left.100 \mathrm{~g}^{-1}\right)$ e às extras $\left(37,60\right.$ a 40,17 a kcal $\left.100 \mathrm{~g}^{-1}\right)$. Esses resultados indicam que as cervejas comuns, elaboradas com menor teor de extrato primitivo, apresentam menos dextrinas e álcool em sua composição e consequentemente são menos calóricas. Já, a adição de mel aumentou o valor calórico na cerveja extra e comum, devido ao aumento nos teores alcoólicos nas cervejas com $40 \%$ de mel (Tabela 3 ). Por outro lado, a adição de mel diminuiu o valor energético na cerveja forte, em função do empobrecimento do teor de extrato (dextrinas principalmente) nessa bebida. As cervejas extras e fortes, dentro de cada categoria de mosto $(0 \%$, $20 \%$ e $40 \%$ de mel), apresentaram maior valor energético em função de sua riqueza em álcool e carboidrato (dextrina) (Tabela 3).

\section{CONCLUSÕES}

Os resultados obtidos neste trabalho permitiram concluir que:

As cervejas comuns apresentaram os menores valores energéticos em relação às cervejas fortes e as extras.
O aumento no teor de extrato primitivo eleva o valor calórico das cervejas.

A presença de mel na formulação aumentou os valores energéticos nas cervejas comuns e extras e diminuiu nas fortes.

Os teores de álcool e de carboidrato foram predominantes nos valores energéticos das cervejas, sendo possível observar uma relação entre esses componentes da cerveja e o seu valor calórico.

\section{REFERÊNCIAS}

AQUARONE, E. et al. Biotecnologia na produção de alimentos. In: ZANCANARO JR., O. Vinagres. São Paulo: Edgard Blücher, 2001. v. 4, p. 183-208.

AMERICAN ASSOCIATION OF CEREAL CHEMISTS. Approved methods of the American Association of Cereal Chemists. 10th ed. St Paul, 2000.

BALLADIN, D. A.; HEADLEY, O. Liquid chromatographic analysis of the main pungent principles of solar dried West Indian ginger Zingiber officinale Roscoe. Renewable Energy, Oxford, v. 18, p. 257-261, 1999.

BRASIL. Ministério da Agricultura, Pecuária e Abastecimento. Instrução normativa n. 36, 14 de outubro de 1999. Estabelece o regulamento técnico para fixação dos padrões de identidade e qualidade para fermentados acéticos. Diário Oficial da Republica Federativa do Brasil, Brasília, DF, 15 out. 1999. Seção 1, p. 76.

CARDOSO, M. das G. Análises físico-químicas de aguardente. In: ___ Produção de aguardente de cana-deaçúcar. Lavras: UFLA/FAEPE, 2001. p. 152173.

FURIATTI, S. et al. Utilização de tomate para elaboração de vinagre. In: SEMINÁRIO DE INICIAÇÃO CIENTÍFICA E TECNOLÓGICA DA UTFPR, 14., 2009, Pato Branco. Anais... Pato Branco: Universidade Tecnológica Federal do Paraná. p. 1-4.

MATSUURA, F. C. A. U.; FOLEGATTI, M. I. S.; SARMENTO, S. B. S. Processamento de mandioca: iniciando um pequeno grande negócio agroindustrial. Brasília, DF: EMBRAPA; SEBRAE, 2003. parte 1. (Série agronegócios).

PALHARIN, L. H. D. C. et al.. Estudo sobre gengibre na medicina popular. Revista Cientifica Eletrônica de Agronomia, Garça, n. 14, p. 1- 4, 2008.

PARRONDO, J. et al. Production of vinegar from Whey. Journal of the Institute of Brewing, London, v.109, p. $358,2003$. 
SARMENTO, S. B. S. Legislação brasileira para derivados de mandioca. Revista Raízes e Amidos Tropicais, Botucatu, v. 6, p. 99-119, 2010.

SPINOSA, W. A. Isolamento, seleção, identificação e parâmetros cinéticos de bactérias acéticas provenientes de indústrias de vinagre. 2002. $215 \mathrm{f}$.

Tese (Doutorado em Ciência de Alimentos)-

Universidade Estadual de Campinas, Campinas, 2002.

TORRES, L. M. Caracterização dos parâmetros técnicos do processo de fabricação de aguardente a partir de gengibre. 2009.105 f. Dissertação (Mestrado em Agronomia/Energia na Agricultura)-Faculdade de Ciências Agronômicas, Universidade Estadual Paulista, Botucatu, 2009.

TORRES, L. M.; LEONEL, M.; MISCHAN, M. M.

Concentração de enzimas amilolíticas na hidrólise do amido de gengibre. Ciência Rural, Santa Maria, v. 42, n. 7, p. 1327-1332, 2012. 